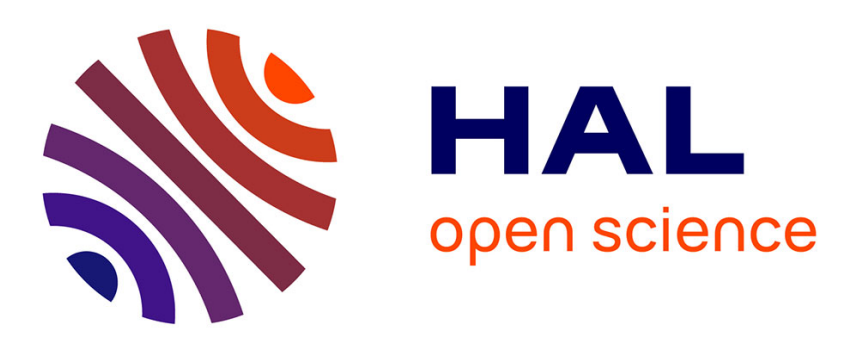

\title{
Comparison of species sensitivity distributions based on population or individual endpoints
}

Rémy Beaudouin, Alexandre R.R. Pery

\section{To cite this version:}

Rémy Beaudouin, Alexandre R.R. Pery. Comparison of species sensitivity distributions based on population or individual endpoints. Environmental Toxicology and Chemistry, 2013, 32 (5), pp.11731177. 10.1002/etc.2148 . ineris-00961806

\section{HAL Id: ineris-00961806 \\ https://hal-ineris.archives-ouvertes.fr/ineris-00961806}

Submitted on 20 Mar 2014

HAL is a multi-disciplinary open access archive for the deposit and dissemination of scientific research documents, whether they are published or not. The documents may come from teaching and research institutions in France or abroad, or from public or private research centers.
L'archive ouverte pluridisciplinaire $\mathbf{H A L}$, est destinée au dépôt et à la diffusion de documents scientifiques de niveau recherche, publiés ou non, émanant des établissements d'enseignement et de recherche français ou étrangers, des laboratoires publics ou privés. 


\section{COMPARISON OF SPECIES SENSITIVITY DISTRIBUTIONS BASED ON POPULATION OR INDIVIDUAL ENDPOINTS}

RÉMY BEAUDOUIN $^{\dagger}$ and ALEXANDRE R.R. PÉRY ${ }^{\dagger *}$

${ }^{\dagger}$ Unit « Models for ecotoxicology and toxicology », INERIS, Verneuil-en-Halatte, France.

* Alexandre Péry. Address: INERIS, Parc ALATA, BP2, 60550 Verneuil-en-Halatte, France; Tel: +33 3445561 26; Fax: +33 3445567 67; E-Mail: alexandre.pery@ineris.fr. 
${ }^{1}$ To whom correspondence may be addressed (alexandre.pery@ineris.fr). 
Abstract-Species Sensitivity Distributions (SSDs) developed from individual and population endpoints were compared based on simulations and a case study. The simulations were performed with five invertebrate species accounting for the diversity of benthic macroinvertebrate communities in large European lowland rivers and for five benthic invertebrates used as laboratory species. Population growth rate EC10 values were, in most of the simulations, higher than the lowest of the EC10 values at individual level. However, for the set of ecologically representative species, HC5 were in majority more protective for population endpoints than for individual endpoints. This was the opposite for the set of laboratory species. Population and individual SSDs were also compared based on existing data on copper for the five laboratory invertebrate species. In this case, the calculated population HC5 value was almost twice the individual value, and we showed much reduced variability between species sensitivities at population level compared to individual level. We conclude that population-based HC5 would generally be more protective than individualbased HC5. However, the change of level could reveal higher homogeneity at population level than at individual level, supporting the use of population-based HC5 to avoid overprotection. We thus advise the derivation of population-based HC5, as soon as it is possible to derive such value with a relevant panel of species.

Keywords-Species sensitivity distributions Population modelling Invertebrates Computer modelling Ecological risk assessment 


\section{INTRODUCTION}

In practice, aquatic ecosystem quality standards are set from compilations of standard single-species toxicity tests results. When enough data are available, species sensitivity distributions (SSDs) can be developed from these compilations. SSDs are cumulative distribution functions estimated from toxicity data obtained for some species' responses and are statistically considered a sample of the responses of all the species composing a community. The fifth percentile level of this distribution (HC5) is the most commonly used value in the practice of using SSDs to set environmental predicted no effect concentrations (PNECs) [1].

To be useful in ecological risk assessment, the biological responses considered in the SSD should be ecologically relevant. In practice, the vast majority of SSDs are built from acute data. A step towards more ecologically relevant SSDs consists in using chronic responses. However, chronic effects on survival, reproduction, or growth can induce very different consequences at population level among species [2]. This is generally ignored, and chronic SSDs are generally derived with data relative to a mixture of endpoints, for instance growth and reproduction, keeping the most sensitive endpoint per species to achieve a conservative estimation [3]. Even when only reproduction is investigated, many sub-endpoints are considered, like sex ratio, development, fecundity or egg masses [4].

Using a same endpoint for all species, which would not depend on test duration, could improve the relevance of the SSD approach. This endpoint could be the population growth rate, which has the additional advantage of proposing an endpoint closer to ecosystem level than individual endpoints and able to integrate many effects (on survival, growth and reproduction) in one single parameter. Population level modeling decreases uncertainty associated with standard toxicity assessment through the prediction of the demographic consequences of the effects of chemicals [5]. 
In this paper, we present different simulation studies and one case study on copper data to study the application of the SSD methodology to the EC10 for population growth rate and compare it with SSD based on individual endpoints. The simulations were performed first with five invertebrate species, accounting for the diversity of benthic macroinvertebrate communities in large European lowland rivers, then with five different benthic macroinvertebrate laboratory species, for which copper data were available.

\section{MATERIALS AND METHODS}

\section{Simulated data}

We compared SSD obtained for individuals and those obtained at population level through 1000 simulations of dose response relationships for survival, growth and reproduction of five invertebrate species accounting for the diversity of benthic macroinvertebrate communities in large European lowland rivers [6]. These species were Chironomus riparius (Insecta: Diptera), Branchiura sowerbyi (Oligochaeta: Tubificidae), Lumbriculus variegatus (Oligochaeta: Lumbriculidae), Valvata piscinalis (Gastropoda: Valvatidae), and Sericostoma personatum (Trichoptera: Sericostomatidae).

The life cycle parameters values in control conditions, which we need for population modelling (juvenile survival $\left(S_{j}\right)$, adult survival $\left(S_{a}\right)$, age at first reproduction $\left(t_{j}\right)$, time between reproduction events $\left(t_{a}\right)$ and fecundity $\left.(F)\right)$, are available in the literature for four out of the five species considered (Table 1). Chironomus riparius is a semelparous species with fecundity around 100 females per female and around two weeks to reach maturity [7]. Branchiura sowerbyi is a hermaphroditic freshwater worm with, in the laboratory, low hatching rate (32\%), high juvenile survival (>80\%) and a lifespan up to 1100 days [8]. Reproduction of Lumbriculus variegatus under laboratory conditions is by asexual fragmentation, during which a worm spontaneously divides into two or more body fragments 
[9]. We assumed it takes about 10 days for individuals to divide in two parts and be able to reproduce again [10]. Valvata piscinalis is a gastropod with high hatchability and survival rates in laboratory conditions [11]. For Sericostoma personatum, only growth and hatching data is available [12]. This species was replaced by another trichoptera species, Cheumatopsyche brevilineata (Trichoptera: Hydropsychidae) for which we had enough data to cover all life cycle parameters, and which has already been proposed for ecotoxicity tests [13].

The dose effect relationship was modeled as a Hill model:

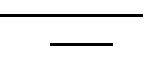

with $C$ the exposure concentration, EC50 the concentration leading to $50 \%$ of effect, and $n$ the slope value.

We performed 1,000 simulations, for the five species, simulating independently at each simulation one dose effect relationship for each endpoint and each species. The effects we considered were a decrease of juvenile survival, a decrease of fecundity and a decrease of the growth rate (resulting in an increase of age at first reproduction). Effects on growth and on reproduction had each $50 \%$ of probability of occurrence (which means that there was $25 \%$ probability that both occurred, and the same probability that none occurred). We performed two sets of simulations with slope values of $n=1$ and $n=4$ accounting for most of the values found for the copper case study (See Table 2), to which we compared the outcomes of the simulations. The values for $n$ were fixed in each set to assess the influence of the slope value on our conclusions. Different lognormal distributions were used for the EC50 values of all the endpoints. The distributions were the same for growth (age at first reproduction) and reproduction (intervals containing $90 \%$ of the values were $[0.1 ; 10]$ ), with higher mean values for juvenile survival (the interval containing $90 \%$ of the values was $[0.5 ; 50]$ ) assuming that lethal effects, even for juveniles would generally occur at higher exposure concentrations than 
sublethal effects. We excluded effects on adult survival, assuming that such effect would occur at high exposure concentrations, and effects on the interval between two reproduction events for such effects are rarely reported in toxicity tests which usually focus on the total number of offspring throughout time.

For each simulation, we calculated SSD on individuals based on the lowest EC10 value among all the effects obtained for each species and SSD on populations based on the EC10 on the population growth rate of each species. To calculate this EC10, we used a generic population dynamics model [14], with a time step of one day:

The population intrinsic growth rate $r$ is the logarithm of $\lambda$. We calculated the dose response relative to $r$ and could estimate the concentration leading to a $10 \%$ reduction compared to control value.

To determine the HC5, i. e. the value of the 5th percentile of the lognormal distribution that is fitted to the species effect concentrations [14], the EC10 values were ordered from the smallest to the largest value. The ordered values were then given a rank using the equation provided by Clements and Newman [15]:

where $i$ is the $i^{\text {th }}$ ranked observation and $N$ the total number of observations. A lognormal model was assumed and the probit transformation of each rank was done. Hence, a linear model could be fitted between the logarithm of the effect concentrations and the probit of the ranks. Simulation and statistical analysis were performed under the R environment [16].

\section{Application to experimental data}

We used the data published by Roman et al. [17]. The authors have previously used these data to derive SSD and calculate HC5 values. These data are composed of reproduction and biomass production for Lumbriculus variegatus, growth and reproduction for Tubifex tubifex, 
growth and emergence for Chironomus riparius, growth for Gammarus pulex and Hyalella azteca, and survival for all species. Authors provide EC10 and EC50 values, which we used to reconstruct the dose response with the Hill model for all endpoints measured for each species. The slope values $(n)$ of the model regression are shown in Table 2.

The biological and ecological characteristics of the five species are available in Table 3. We already presented Lumbriculus variegatus and Chironomus riparius species. For Tubifex tubifex, we used data from Bettinetti and Provini [18]. They used sexually mature worms at their first reproductive event (approximately six weeks) and monitored reproduction after 28 days. McCahon and Pascoe [19] showed that Gammarus Pulex needed 130 days to reach sexual maturity, with $70 \%$ of organisms surviving until maturity. Cold and Forbes [20] found a mean number of offspring of 13 per female over a 13 days period with $80 \%$ of the females reproducing. For Hyalella azteca, Péry et al. [21] found a mean reproduction around 14 over a 28 days period, young survival around 0.9 and maturity was reached after 30 days. In a first step, we performed simulations with these five species in the same way as previously to assess the differences in HC5 derivations depending on the choice of species. Then we calculated the HC5 for these five species exposed to copper.

\section{RESULTS}

For the simulations with the ecologically representative species in Table 1, the lowest EC10 value at individual level was lower than the EC10 value at population level in $73.8 \%$ of the simulations $(5,000$ values) with $n=1$, and in $62.9 \%$ of the simulations with $n=4(5,000$ values). The comparison between individual and population endpoints was modified for HC5. Indeed, HC5 calculated for the population growth rates EC10 was lower than the HC5 based on the lowest EC10 values in $56.9 \%$ of the simulations (1,000 values) with $n=1$, and in $60.9 \%$ of the simulations with $n=4$ (1,000 values). This modification when going from EC10 to HC5 
values is due to the slope of the SSD regressions. Indeed, in respectively for $n=1$ and $n=4$, $91.5 \%$ and $91.6 \%$ of the simulations, the slope of the SSD regression was lower for population endpoints compared to individual ones, indicating more variability between species endpoints at population level than at individual level. The ratios between population and individual HC5 values were in the interval $[0.2 ; 5]$ in $84 \%$ of the cases for $n=1$, and in $82 \%$ of the cases for $n=4$.

For the simulations with the species in Table 3, the lowest EC10 value at individual level was lower than the EC10 value at population level in $89.7 \%$ of the simulations $(5,000$ values $)$ with $n=1$, and in $74 \%$ of the simulations with $n=4$ (5,000 values). The HC5 calculated for the population growth rates EC10 was lower than the HC5 based on the lowest EC10 values in $44.3 \%$ of the simulations (1,000 values) with $n=1$, and in $37.8 \%$ of the simulations with $n=4$ (1,000 values). In $85.2 \%$ and $75.7 \%$ of the simulations respectively for $n=1$ and $n=4$, the slope of the SSD regression was lower for population endpoints compared to individual ones. The ratios between population and individual $\mathrm{HC} 5$ values were in the interval $[0.2 ; 5]$ in $81 \%$ of the cases for $n=1$, and in $100 \%$ of the cases for $n=4$.

For the calculations based on the copper toxicity data, EC10 values at population level are presented in Table 2. Population and lowest individual EC10 values are close, with at most two fold of differences. There is also less variability between species among EC10 population values than among EC10 individual values.

Figure 1 and Figure 2 present the population growth rates of the five species as a function of exposure concentration together with the SSD for individuals and populations. The HC5 for individuals was estimated at $27.8 \mathrm{mg} / \mathrm{kg}$, and the HC5 for populations at $44.4 \mathrm{mg} / \mathrm{kg}$. The slope of the SSD regression for individual SSD was 2.1. It was 3.5 at population level.

\section{DISCUSSION}


In our simulations, populations EC10 values were most of the time higher than the lowest EC10 at individual level, but the slope of the regression to derive the SSD was generally lower at population than at individual level. In general, HC5 values derived with the ecologically relevant species were lower at population level compared to individual level (this was the case in around $60 \%$ of the simulations). This was the opposite for the species used for the copper study (lower population-based HC5 than individual-based HC5 in around 40\% of the simulations). One explanation for this slight difference would be that the current species used in routine laboratory tests have low variability between their life history strategies compared to species representing actual communities. Indeed, selected laboratory species have short life cycle (rapid growth) and high fecundity resulting in a high population growth rate. In general (more than $80 \%$ of the simulations), individual and population HC5 values did not differ by more than a factor of 5 . This factor of 5 is the highest safety factor recommended to derive a PNEC from a SSD [1].

In the copper case study, population HC5 value was calculated as 1.6 fold the individual value. This was a direct consequence of a high slope of the SSD description at population level, indicating that there was not much difference between species sensitivities at population level, as the slope accounts for the extent of variability among species. The ratio between population and individual slopes belongs to the part of the distribution below $5 \%$ for the simulations both with the species of Table 1 and of Table 3 with either $n=1$ or $n=4$, indicating much lower variability among population endpoints between the species exposed to copper than expected based on their life-cycle traits values only. We propose the following explanation. In our simulations, we did not introduce any correlation between sensitivity of life cycle parameters and the sensitivity of the population dynamics to these parameters. Organisms' sensitivity to stress is a function of their biology, and can be predicted from species traits [22]. It is likely that in case of pollutants present widely in the environment, 
organisms are adapted from long to this pollutant. Hence, phenotypes more protective for the life history traits with the greater impact on their fitness (and hence on population dynamics at the population level) were selected in the past. For instance, the sensitivity of $C$. riparius life cycle parameters to copper is exactly in the opposite order as the sensitivity of population dynamics to these parameters [23-24]. Similarly, the endpoint impacted at the lowest zinc concentration for the species Valvata piscinalis is one of the endpoint for which population dynamics is the less sensitive [25]. More generally, it has been shown that changes in traits having a high sensitivity to chemical toxicants have a relatively low impact on population growth rate, compared to other life-cycle traits [26]. Our conclusions can obviously not be easily generated because they rely on one chemical only, copper, which is a metal with much specificity relative to acclimatization, bio-availability, and essentiality.

The question of using acute or chronic data to derive ecologically-relevant SSD is an important issue. It has been shown for many substances, including metals, pesticides, organic and inorganic compounds, that HC5 calculated based on laboratory-generated single-species chronic studies are protective of model ecosystem [27-29]. Raimondo et al. [30] evaluated the protectiveness of SSD first and fifth percentile hazard concentrations (HC1, HC5) relative to the application of safety factors using 68 SSDs generated from 1,482 acute (lethal concentration of $50 \%$, or LC50) toxicity records for 291 species, including 24 endangered species (20 fish, four mussels). They showed that SSD approach is more protective, especially for endangered species, than applying safety factors.

With data collected for 16 insecticides, Maltby et al. [31] showed that the lower HC5 (95\% protection with $95 \%$ confidence) estimate, based on SSDs with acute data, was protective of adverse ecological effects in freshwater mesocosms, but that the corresponding median HC5 (95\% protection level with $50 \%$ confidence) was generally protective of single applications of insecticide but not of continuous or multiple applications. In the latter cases, a safety factor of 
at least five should be applied to the median HC5. Comparison between SSDs based on acute data and semi-field studies showed that HC5 should be divided by a factor of three to protect ecosystems under long-term exposure to fungicides [32]. For herbicides, the lower limit of acute $\mathrm{HC} 5$ and the median value of chronic HC5 have been found to be protective of adverse effects in aquatic micro/mesocosms even under a long-term exposure regime [33]. In the present study, we showed through our simulations that there is a same probability for a chronic individual-based HC5 to be lower than a population-based HC5 than the opposite, with only slight differences related to the species composition. In general, population growth rate is equally or less sensitive to toxicant exposure than any of the individual life-history trait [34], as we showed here, but, in our simulations the slope for population-based SSDs was, in general, lower than the one for individual-based SSDs. In the case of copper, the populationbased HC5 was higher than the chronic HC5, accounting for some related toxicity responses between species at population level. This suggests that population-based HC5 is theoretically as sensitive as chronic HC5 but could account for correlations in the toxicological responses of the different species, resulting in an HC5 value between chronic and acute HC5 values that may avoid overprotection. We thus advise the derivation of population-based HC5, as soon as it is possible to derive such value with a relevant panel of species.

Acknowledgement- Authors would like to thank Céline Brochot, Cleo Tebby, Florence Zeman and Enrico Mombelli, so as anonymous reviewers who contributed to improve the quality of this manuscript. The present study was supported by the French Ministry in charge of ecology and sustainable development, within the framework of Programme 190 and by the National Research Agency (ANR) within the project AMORE (contract number: no. 2009, CESA 15 01). 


\section{REFERENCES}

1. EU. 2003. Technical guidance document on risk assessment. EUR 20418 EN/2.

2. Forbes VE, Calow P. 2002. Species sensitivity distributions revisited: a critical appraisal. Hum Ecol Risk Assess 8:473-492.

3. De Schamphelaere KAC, Stubblefield W, Rodriguez P, Vleminckx K, Janssen CR. 2010. The chronic toxicity of molybdate to freshwater organisms. I. Generating reliable effects data. Sci Tot Environ 408:5362-5371.

4. Caldwell DJ, Mastrocco F, Hutchinson TH, Lange R, Heijerick D, Janssen C, Anderson PD, Sumpter JP. 2008. Derivation of an aquatic predicted no-effect concentration for the synthetic hormone, 17 alpha-ethinyl estradiol. Environ Sci Technol 42:7046-7054.

5. Forbes VE, Calow P, Sibly RM. 2008. The extrapolation problem and how population modeling can help. Environ Toxicol Chem 27:1987-1994.

6. Ducrot V, Usseglio-Polatera P, Péry ARR, Mouthon J, Lafont M, Roger MC, Garric J, Ferard JF. 2005. Using aquatic macroinvertebrate species traits to build test batteries for sediment toxicity assessment: accounting for the diversity of potential responses to toxicants. Environ Toxicol Chem 24:2306-2315.

7. Péry ARR, Mons R, Flammarion P, Lagadic L, Garric J. 2002. A modeling approach to link food availability, growth, emergence and reproduction for the midge Chironomus riparius. Environ Toxicol Chem 21:2507-2513.

8. Ducrot V, Péry ARR, Quéau H, Mons R, Lafont M, Garric J. 2007. Rearing ansd estimation of life-cycle parameters of the tubicifid worm Branchiura sowerbyi: Application to ecotoxicity testing. Sci Tot Environ 384:252-263. 
9. Sardo AM, Soares AMVM, Gerhardt A. 2007. Behavior, growth and reproduction of Lumbriculus variegatus (Oligochaete) in different sediment types. Hum Ecol Risk Assess 13:519-526.

10. Leppänen MT, Kukkonen JVK. 1998. Relationship between reproduction, sediment type, and feeding activity of Lumbriculus variegatus (Muller): implications for sediment toxicity testing. Environ Toxicol Chem 17:2196-2202.

11. Ducrot V, Cognat C, Mons R, Mouthon J, Garric J. 2006. Development of rearing and testing protocols for a new frshwater sediment test species: The gastropod Valvata piscinalis. Chemosphere 62:1272-1281.

12. Wagner R. 1990. A laboratory study on the life-cycle of Sericostoma-personatum (Kirby and Spence) and light/dark-dependence food-consumption. Hydrobiologia 208:201-212.

13. Yokoyama A, Hamaguchi K, Ohtsu K, Ishihara S, Kobara Y, Horio T, Endo S. 2009. A method for mass-rearig caddisfly, Cheumatopsyche brevilineata (Iwata) (Trichoptera: Hydropsychidae), as a new test organism for assessing the impact of insecticides on riverine insects. Appl Entomol Zool 44:195-201.

14. Calow P, Sibly RM, Forbes V. 1997. Risk assessment on the basis of simplified lifehistory scenarios. Environ Toxicol Chem 16:1983-1989.

15. Clements WH, Newman MC. 2002. Community Ecotoxicology. John Wiley and Sons, Chichester, United Kingdom, 336 pp.

16. R Development Core Team. 2010. R: A language and environment for statistical computing. R Foundation for Statistical Computing, Vienna, Austria. ISBN 3-90005107-0, URL http://www.R-project.org/. 
17. Roman YE, De Schamphelaere KAC, Nguyen LTH, Janssen CR. 2007. Chronic toxicity of copper to five benthic invertebrates in laboratory-formulated sediment: sensitivity comparison and preliminary risk assessment. Sci Tot Environ 387:128-140.

18. Bettini R, Provini A. 2002. Toxicity of 4-nonylphenol to Tubifex tubifex and Chironomus riparius in 28-day whole-sediment tests. Ecotoxicol Environ Saf 53:113121.

19. McCahon CP, Pascoe D. 1988. Use of Gammarus pulex (L.) in safety evaluation tests: culture and selection of a sensitive life stage. Ecotoxicol Environ Saf 15:245-252.

20. Cold A, Forbes VE. 2004. Consequences of a short pulse of pesticide exposure for survival and reproduction of Gammarus pulex. Aquat Toxicol 67:287-299.

21. Péry ARR, Gust M, Vollat B, Mons R, Ramil M, Fink G, Ternes T, Garric J. 2008. Fluoxetine effects assessment on the life cycle of aquatic invertebrates. Chemosphere 73:300-304.

22. Baird DJ, Van den Brink PJ. 2007. Using biological traits to predict species sensitivity to toxic substances. Ecotoxicol Environ Saf 67:296-301.

23. Péry ARR, Mons R, Garric J. 2004. Energy-based modeling to study population growth rate and production for the midge Chironomus riparius in ecotoxicological risk assessment. Ecotoxicology 13:647-656.

24. Péry ARR, Geffard A, Garric J. 2006. Mechanistic models to perform population risk assessment with the midge Chironomus riparius: application to heavy metals. Environ Sci Technol 40:6026-6031.

25. Ducrot V, Péry ARR, Mons R, Quéau H, Charles S, Garric J. 2007. Dynamic energy budget as a basis to model population-level effects of zinc-spiked sediments in the gastropod Valvata piscinalis. Environ Toxicol Chem 26:1774-1783. 
26. Forbes VE, Olsen M, Palmqvist A, Calow P. 2010. Environmentally sensitive lifecycle traits have low elasticity: implications for theory and practice. Ecol Appl 20:1449-1455.

27. Versteeg DJ, Belanger SE, Carr GJ. 1999. Understanding single-species and model ecosystem sensitivity : Data-based comparison. Environ Toxicol Chem 6:1329-1346.

28. Schmitt-Jansen M, Altenburger R. 2005. Predicting and observing responses of algal communities to photosystem II-herbicide exposure using pollution-induced community tolerance and species-sensitivity distributions. Environ Toxicol Chem 24:304-312.

29. Selck H, Riemann B, Christoffersen K, Forbes VE, Gustavson K, Hansen BW, Jacobsen JA, Kusk OK, Petersen S. 2002. Comparing sensitivity of ecotoxicological effect endpoints between laboratory and field. Ecotoxicol Environ Saf 52:97-112.

30. Raimondo S, Vivian DN, Delos C, Barron MG. 2008. Protectiveness of species sensitivity distribution hazard concentrations for acute toxicity used in endangered species risk assessment. Environ Toxicol Chem 27:2599-2607.

31. Maltby L, Blake N, Brock TCM, van den Brink TJ. 2005. Insecticide species sensitivity distributions: importance of test species selection and relevance to aquatic ecosystems. Environ Toxicol Chem 24:379-388.

32. Maltby L, Brock TCM, van den Brink PJ. 2009. Fungicide risk assessment for aquatic ecosystems: importance of interspecific variation, toxic mode of action, and exposure regime. Environ Sci Technol 43:7556-7563.

33. Van den Brink PJ, Blake N, Brock TCM, Maltby L. 2006. Predictive value of species sensitivity distributions for effects of herbicides in freshwater ecosystems. Human Ecol Risk Assess 12:645-674. 
34. Forbes VE, Calow P. 1999. Is the per capita rate of increase a good measure of population-level effects in ecotoxicology? Environ Toxicol Chem 18:1544-1556. 
Figure legends

Fig. 1. Population growth rate and decrease of population growth rate as a function of exposure concentration for the 5 species of the copper case study.
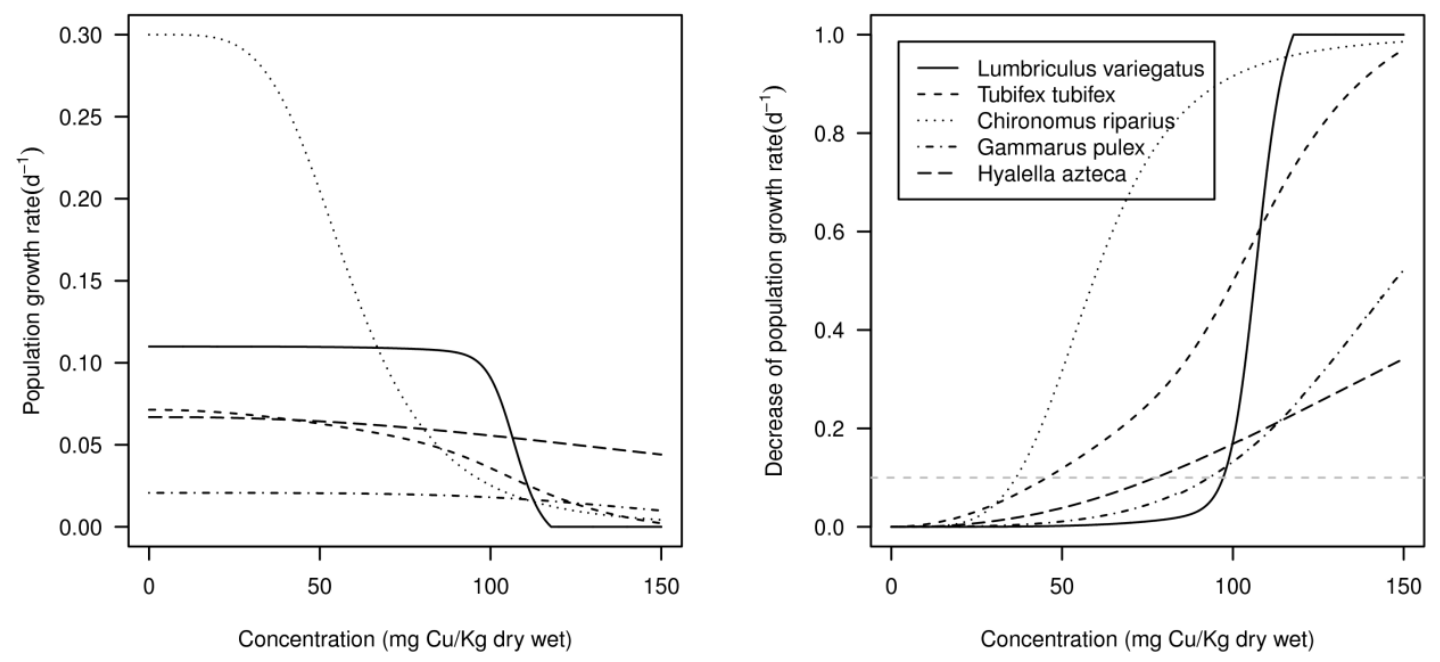

Fig. 2. SSD for the copper case study based on EC10 values at population level (Black points and full line) or at the individual level (white points and dotted line). Grey lines represent the value of the 5th percentile of the lognormal distribution.

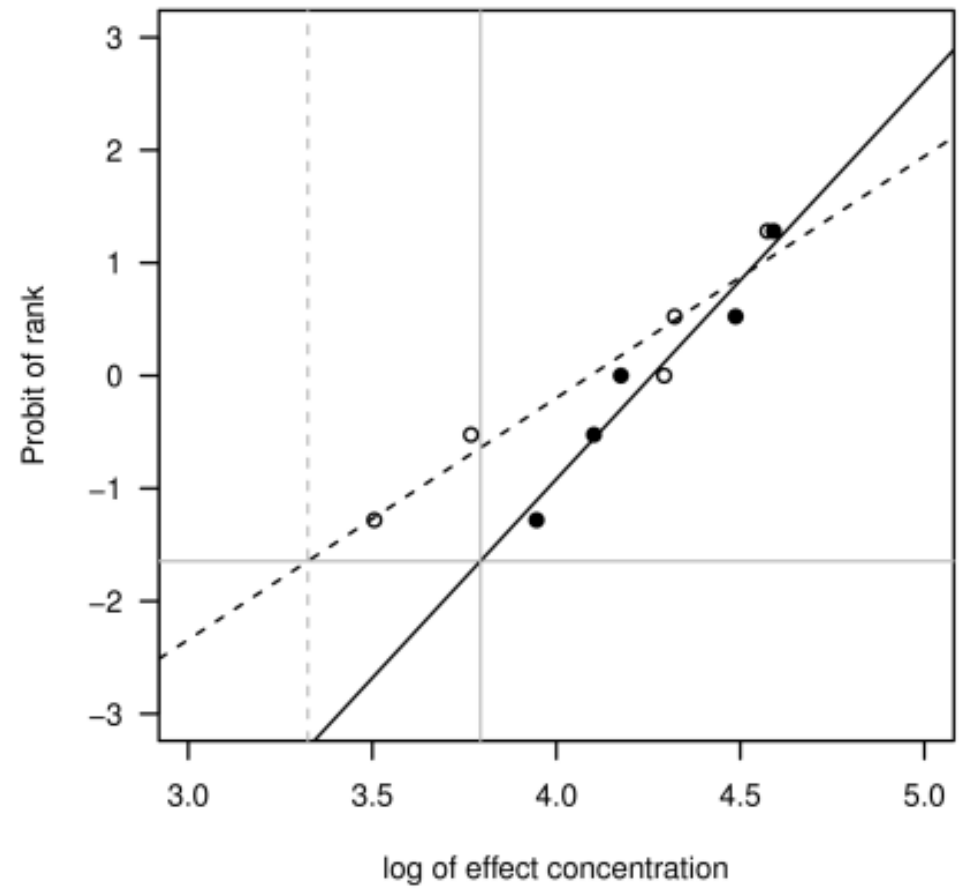


Table 1. Life cycle parameters used for the 5 species proposed by Ducrot et al. (2005) Juvenile survival $\left(S_{j}\right)$, adult survival $\left(S_{a}\right)$, age at first reproduction $\left(t_{j}\right)$, time between reproduction events $\left(t_{a}\right)$ and fecundity $\left.(F)\right)$ and population growth rate $(r)$.

\begin{tabular}{lccccccc}
\hline Species & $S_{j}$ & $S_{a}$ & $t_{j}(d)$ & $t_{a}(d)$ & $F$ & $r$ & Reference \\
& & & & & & & \\
\hline Lumbriculus variegatus & 1 & 1 & 10 & 10 & 2 & 0.110 & {$[8-9]$} \\
Branchiura sowerbyi & 0.8 & 1 & 60 & 160 & 20 & 0.046 & {$[7]$.} \\
Chironomus riparius & 0.9 & 0 & 15 & 0 & 100 & 0.299 & {$[6]$} \\
Valvata piscinalis & 1 & 0.99 & 56 & 41 & 120 & 0.086 & {$[10]$} \\
& & 4 & & & & & \\
Cheumatopsyche & 0.09 & 0 & 172 & 0 & 70 & 0.011 & {$[12]$} \\
brevilineata & & & & & & & \\
\hline
\end{tabular}


Table 2. EC10 values obtained for the 5 species of the copper case study (lowest EC10 ind is the lowest EC10 value obtained for the individual endpoints). All values are expressed in mg $\mathrm{Cu} / \mathrm{Kg}$ dry wet. The slope values $(n)$ for the dose responses with the Hill models are also indicated.

\begin{tabular}{lccccc}
\hline & L. variegatus & T.tubifex & C. riparius & G. pulex & H. azteca \\
\hline EC10 pop & 98.5 & 51.7 & 60.4 & 65.0 & 88.85 \\
Lowest EC10 ind & 96.9 & 43.3 & 33.3 & 73.2 & 75.3 \\
EC10 growth & & 43.3 & 92.5 & 102 & 75.3 \\
EC10 reproduction & 96.9 & 79.2 & & & \\
EC10 juvenile survival & 126 & 160 & 33.3 & 73.2 & \\
EC10 adult survival & 126 & 160 & & & \\
$n$ EC10 growth & & 2.1 & 4.5 & 5.9 & \\
$n$ EC10 reproduction & 27.4 & 10.3 & & 3.0 & \\
$n$ EC10 juvenile survival & 4.3 & 3.1 & 3.8 & & \\
$n$ EC10 adult survival & 4.3 & 3.1 & & & \\
\hline
\end{tabular}


Table 3. Life cycle parameters used for the 5 species in the copper case studies. (Juvenile survival $\left(S_{j}\right)$, adult survival $\left(S_{a}\right)$, age at first reproduction $\left(t_{j}\right)$, time between reproduction events $\left(t_{a}\right)$ and fecundity $\left.(F)\right)$ and population growth rate $(r)$

\begin{tabular}{lccccccc}
\hline \multicolumn{1}{c}{ Species } & $S_{j}$ & $S_{a}$ & $t_{j}(d)$ & $t_{a}(d)$ & $F$ & $r$ & Reference \\
\hline Lumbriculus variegatus & 1 & 1 & 10 & 10 & 2 & 0.110 & {$[8-9]$} \\
Tubifex tubifex & 1 & 1 & 40 & 28 & 15 & 0.071 & {$[17]$} \\
Chironomus riparius & 0.9 & 0 & 15 & 0 & 100 & 0.299 & {$[6]$} \\
Gammarux pulex & 0.7 & 1 & 130 & 13 & 5 & 0.021 & {$[18-19]$} \\
Hyalella azteca & 0.9 & 1 & 30 & 28 & 7 & 0.067 & {$[20]$} \\
& & & & & & & \\
\end{tabular}

